\title{
IMPLANTAÇÃO DO PROGRAMA 5S NO ESTOQUE DE UMA CONTRUTORA CIVIL: ESTUDO DE CASO NA CIDADE DE PASSOS - MG
}

\section{IMPLEMENTATION OF THE 5S PROGRAM IN THE STOCK OF A CIVIL CONSTRUCTION COMPANY: CASE STUDY IN THE CITY OF PASSOS - MG}

\section{K. A. F. SANJULIÃO' ${ }^{1}$, L. F. SOUZA¹, T. V. RODRIGUES*2, A. A. SANTOS ${ }^{1}$ AND C. H. FERNADES ${ }^{2}$}

${ }^{1}$ Universidade do Estado de Minas Gerais, UEMG, Engenharia de Produção, Passos, Minas Gerais, Brasil

${ }^{2}$ Universidade Tecnológica Federal do Paraná, UTFPR, Engenharia de Produção, Ponta Grossa, Paraná, Brasil

" Corresponding author. Universidade Tecnológica Federal do Paraná, UTFPR, Engenharia de Produção, Ponta Grossa, Paraná, Brasil: +55 35 99129-6603

e-mail addressl: thales.volpe@hotmail.com (T.V.Rodrigues).

\section{A R T I C L E I N F O}

Article history:

Received 2020-06-25

Accepted 2020-09-04

Available online 2020-09-04

palavras-chave

Gestão de estoque

Produção enxuta

$5 \mathrm{~S}$

Construção civil

\section{keywords}

Inventory management

Lean production

$5 \mathrm{~S}$

Construction

\section{A B S T R A C T}

With globalization, the consumer has gained prominence and importance in the current market. To retain a customer and remain competitive, it is necessary for companies to seek improvements in their internal and external processes. Because of this, organizations see the need to invest in technologies and tools to improve their processes, and a philosophy that has been adopted is the practice of Lean Production. This philosophy aims to eliminate activities that do not add value to the process, and the $5 S$ tool in particular proposes better organization, cleanliness and safety in the implemented environment. Therefore, the present work carried out a case study that aimed to implement the 5 S program in the stock of a civil construction company located in the municipality of Passos, southwest of Minas Gerais. Interviews and onsite observations were carried out to get to know and evaluate the study environment. With data in hand, an action plan was developed to direct the activities to be developed in each " $S$ " of the tool. After the implementation of the tool, it was possible to detect changes in inventory management and in the quality and safety of employees.

R E S UM O

Com a globalização, o consumidor ganhou destaque e importância no mercado atual. Para fidelizar um cliente e se manter competitiva, faz se necessário que as empresas busquem por melhorias em seus processos internos e externos. Devido a isso, as organizações veem a necessidade de investir em tecnologias e ferramentas para melhorar seus processos, e uma filosofia que vem sendo adotada é a pratica da Produção Enxuta. Esta filosofia visa eliminar as atividades que não agregam valor ao processo, e a ferramenta $5 \mathrm{~S}$ em particular propõe uma melhor organização, limpeza e segurança no ambiente implementada. Diante disso, o presente trabalho realizou um estudo de caso que teve como objetivo implantar o programa 5S no estoque de uma construtora civil localizada no município de Passos, sudoeste de Minas Gerais. Foram realizadas entrevistas e observações in loco para conhecer e avaliar o ambiente em estudo. Com dados em mãos elaborou-se um plano de ação para direcionar as atividades a serem desenvolvidas em cada " $S$ " da ferramenta. Após a implantação da ferramenta foi possivel detectar transformações na gestão de estoques e na qualidade e segurança dos funcionários. 
No mercado atual, devido à globalização, os clientes exigem cada vez mais qualidade nos produtos e serviços que adquirem. Deste modo, as empresas estão sempre em busca de melhorias e novas competências para permanecerem no mercado.

A competitividade não trata apenas de rivalizar com os concorrentes, mas também consigo mesmo, aumentando seu próprio desempenho. Assim, faz-se necessário que toda empresa tenha uma boa gestão de processos internos, além de uma organização estruturada.

Como um aliado para esse processo de melhoria contínua, Ohno (1997) diz que o Sistema Toyota de Produção, também conhecido como Lean Manufacturing, foi desenvolvido baseado na eliminação contínua de desperdícios. Existem várias ferramentas que compõe o Sistema Toyota de Produção, entre elas estão: kaizen, kanban, poka-yoke, mapeamento de fluxo de valor, estudo de tempos, manutenção total da produção, padronização e 5S. A prática destas atividades resulta em transformações no processo empresarial.

De acordo com Womack e Jones (1996), a principal filosofia da Produção Enxuta é produzir mais usando menos recursos. Para isso, o primeiro passo para a implementação do Lean é definir o que é valor. Valor pode ser definido de diferentes formas, porém as empresas devem entender o seu significado através dos olhos dos clientes. O segundo passo, descrito pelos autores, é definir o fluxo de valor, que são as atividades necessárias para produzir o produto ou serviço.

Os princípios da Produção Enxuta são genéricos e podem ser aplicados em ambientes industriais ou administrativos, inclusive no setor da construção civil. Frente ao exposto, este trabalho visou aplicar uma das técnicas de Lean Manufacturing, o programa 5S, em uma empresa do ramo de construção civil. E por meio da aplicação desta ferramenta, alcançar uma melhora no sistema empresarial, em termos de minimização de desperdícios, gestão de estoques, e um melhor aproveitamento de tempo e espaço.

O desenvolvimento de um estudo de caso em uma construtora civil se justifica pela alta concorrência na região quanto ao segmento em estudo e, também, para garantir a sua sobrevivência no mercado. Visto que, o valor do produto final (imóvel) é imposto, com a implementação de melhorias nos processos de produção e é possível aumentar a margem de lucro, ou ganhar de seus concorrentes oferecendo um preço mais baixo.

Para tanto, o presente trabalho foi estruturado em tópicos. Primeiramente, foi realizada uma revisão teórica a fim de ampliar a compreensão acerca do assunto. Conseguinte, foi descrito o método de pesquisa aplicado e uma breve apresentação da empresa em estudo. Após essa apresentação, foi retratado o desenvolvimento da pesquisa, seguido das considerações finais e referências obtidos neste trabalho.

\section{REFERENCIAL TEÓRICO}

\subsection{O Programa 5S}

O responsável pela criação do $5 \mathrm{~S}$ é o Engenheiro Químico japonês Kauru Ishikawa, principal criador de conceitos e ferramentas de qualidade do Japão. Além desta ferramenta, várias metodologias foram criadas por Ishikawa e outros estudiosos a fim de garantir a Qualidade Total e o aumento da competitividade entre as empresas numa época difícil e com grande necessidade de reestruturação (FARIA et al., 2014; MATOS et al., 2014).

No Brasil, a aplicação de ferramentas e a criação de ambientes que visam a Qualidade Total nas empresas, deram início apenas na década de 90. Ou seja, a busca por competitividade e melhoria contínua em nosso país ocorreu de maneira bastante tardia, em relação a países desenvolvidos como o Japão (FARIA et al., 2014).

O principal conceito do 5S é a promoção da organização, disciplina e limpeza no local de trabalho, proporcionando aos colaboradores um ambiente agradável, seguro e produtivo. Além disso, incentiva o pessoal a trabalhar em equipe, despertando a motivação das pessoas, a prática de novas ideias, minimizando custos e desperdícios e, melhorando, então, a qualidade na empresa (OLIVEIRA et al., 2015).

\subsection{Seiri - Senso de Utilização, Descarte ou Seleção}

$\mathrm{O}$ primeiro senso refere-se à identificação de máquinas, equipamentos, ferramentas, materiais, utensílios, dados e informações que são necessários, a fim de descartar o que é desnecessário e facilitar a execução das atividades na empresa. A avaliação daquilo que é realmente necessário não é uma tarefa fácil, pois o ser humano tem o hábito de guardar objetos com o pensamento de que no futuro eles possam ter utilidade, ou como se os mesmos fossem uma relíquia (MATOS et al., 2014).

Costa et al. (2014-7) citam, também, quais as principais vantagens deste senso, sendo:

- Aumento do espaço disponível;

- Aumento da segurança do ambiente;

- Facilidade na limpeza e sua manutenção;

- Maior controle do estoque;

- Minimização de custos;

- Disposição mental para a qualidade;

- Reaproveitamento dos recursos da empresa;

- Realocação de funcionários;

- Redução da burocracia.

\subsection{Seiton - Senso de Arrumação ou Organização}

$\mathrm{O}$ segundo senso refere-se à organização e fácil identificação de máquinas, equipamentos, ferramentas, materiais, informações e tudo o que for necessário para a execução das atividades da empresa, a fim de obter maior produtividade e menos esforços. Neste caso, o propósito é garantir cada coisa no seu devido lugar e de maneira constante (FARIA et al., 2014).

\subsection{Seiso - Senso de Limpeza}

O terceiro ñSò estabelece a necessidade de extinguir a sujeira e materiais em desuso, a fim de manter um ambiente 
limpo e agradável, bem como manter dados e informações atualizadas, garantindo tomadas de decisões mais eficazes. Cada pessoa deve ser responsável por manter seu posto de trabalho limpo e organizado, deve ser conscientizada para não sujá-lo e, também, se preocupar com as áreas comuns, o que deve ser responsabilidade de todos (FARIA et al., 2014; LAZZAROTTO et al., 2011).

Para conseguir manter este senso em bom funcionamento, devem-se eliminar as fontes de contaminações e sujidades, pintar os diversos postos de trabalho com cores claras e harmoniosas, fazer revezamento ou nomear um responsável pela limpeza de cada local (caso não seja possível que os colaboradores se responsabilizem pelos seus postos) (OLIVEIRA et al., 2015; VITAL et al., 2015).

\subsection{Seiketsu - Senso de Saúde, Higiene ou Padronização}

O quarto ñSò pressupõe que o ambiente e condições de trabalho devem ser mantidos de forma favorável à saúde, segurança e bem estar do trabalhador, respeitando suas limitações físicas, mentais e emocionais. Este senso é o principal resultado dos três anteriores, pois um local de trabalho ordenado, organizado e limpo beneficia e reflete positivamente na saúde, higiene e segurança dos colaboradores (MATOS et al., 2014).

- De acordo com Costa et al. (2014), os principais benefícios trazidos com a aplicação deste senso são:

- Bem estar físico, mental e emocional dos colaboradores;

- Melhoria da imagem dos postos de trabalho;

- Melhoria da imagem externa da empresa;

- Maior conservação de máquinas, equipamentos e ferramentas;

- Redução de desperdícios;

- Ambiente de trabalho agradável e seguro.

\subsection{Shitsuke - Senso de Disciplina}

O quinto e último senso estabelece que a necessidade de cumprir tudo o que foi estabelecido nos passos anteriores Significa que o processo está basicamente consolidado, necessitando apenas manter os bons hábitos e buscar a melhoria contínua dos processos referentes ao programa (VITAL et al., 2015; SILVA et al., 2015).

\section{MÉTODO DE PESQUISA}

São vários os métodos de pesquisa que podem ser utilizados para a elaboração de trabalhos científicos. Os principais e mais aplicados métodos são a pesquisa-ação, a modelagem e simulação, a pesquisa bibliográfica, o levantamento tipo survey e, o estudo de caso (YIN, 2005; MIGUEL et al., 2010).

O presente trabalho teve como objetivo a implementação da ferramenta $5 \mathrm{~S}$ no estoque de uma construtora, em que o pesquisador obteve conhecimentos sobre o assunto abordado em relação ao objeto de estudo, sugeriu hipóteses e/ou desenvolveu as teorias adquiridas durante sua pesquisa. Assim, o método que se caracterizou melhor para este tipo de trabalho foi o estudo de caso.

Conceituando este método, o estudo de caso é uma abordagem metodológica de cunho investigativo, permitindo a compreensão, exploração ou descrição de contextos bastante complexos, aos quais se tem o envolvimento de diversos fatores. Permite também, uma maior interpretação dos processos de trabalho do objeto de estudo, tudo de maneira real e detalhada (ANTUNES; ANTONIOLI FILHO; CALARGE, 2015).

Por meio deste método, podem-se efetuar abordagens qualitativas e/ou quantitativas. Dada a natureza das variáveis pesquisadas para desenvolvimento do presente trabalho, justifica-se a utilização da abordagem quantitativa devido à necessidade de efetuar medições e comparativos dos tempos gastos antes e após a aplicação da ferramenta $5 \mathrm{~S}$ e, na qualitativa, o pesquisador obtêm informações não numéricas que esclarecem e facilitam a elaboração de 2 (duas) etapas que compõem o estudo de caso, a de análise de dados e a de geração de relatório.

A fase de definição de uma estrutura conceitual teórica implica em pesquisas e embasamentos nas diversas literaturas referentes ao tema a ser abordado nos trabalhos científicos. Os principais meios de pesquisas são: livros, artigos, revistas científicas, sites, normas, leis, entre outros. Então, foi feito um levantamento bibliográfico a respeito dos trabalhos sobre as técnicas de Produção Enxuta com enfoque na ferramenta de organização 5S. Por meio desta pesquisa, pôde-se perceber o grau de importância da aplicação desta ferramenta em diversos ramos de atuação das organizações.

Para execução do presente trabalho, foi escolhido um único caso. $\mathrm{O}$ mesmo pode ser classificado como sendo longitudinal, pois de certa forma, investiga e estuda a situação atual do objeto de estudo.

A unidade pesquisada foi o departamento de estoque de uma empresa do ramo da Construção Civil localizada na cidade de Passos, no estado de Minas Gerais. A coleta de dados foi realizada por meio de visitas ao depósito, entrevistas com funcionários, análise de documentos (previamente consentida pela empresa) tais como relatórios de estoque, planilhas de controle, e cronometragem de tempos de execução das atividades desempenhadas pelos colaboradores.

A condução do teste piloto não foi desenvolvida pelo pesquisador e abordada no presente trabalho. A aplicação da ferramenta $5 \mathrm{~S}$ não demanda o desenvolvimento de um teste piloto, devido à natureza de estruturação desta ferramenta.

O primeiro passo para a efetivação da coleta de dados foi a observação in loco e a aplicação de entrevistas com os colaboradores, a fim de conhecer a situação em que a empresa se encontra e como a mesma atua. Por meio de visitas e observação direta ao departamento estudado, foram coletadas informações referentes aos métodos de trabalho e organização do layout físico do depósito.

Também, com o uso de um aparelho celular, foram efetuadas cronometragens das atividades e fotos foram tiradas para registro e futuras comparações do antes e depois da aplicação da ferramenta.

Após a coleta dos dados, foi feita uma filtragem dos dados com o objetivo de se obter apenas os que são relevantes 
para condução do estudo. Com essa filtragem o número de produtos em estoque, formas de identificação de materiais, tempos gasto pelos funcionários procurando produtos, e condições ambientais de saúde, segurança e limpeza, foram considerados pontos relevantes para a condução deste estudo.

Todas as informações obtidas pelas etapas anteriores do estudo de caso se transformam em um relatório de pesquisa, ou seja, é o que resulta em projetos, artigos e demais trabalhos científicos. Tais resultados devem estar completamente ligados ao referencial teórico do trabalho para que, assim, os mesmos se associem a novas teorias e sirvam de apoio à condução de trabalhos futuros (MIGUEL, 2007).

\section{RESULTADOS E DISCUSSÕES}

\subsection{Descrição da Empresa em Estudo}

Fundada em outubro de 2012, com instalação na cidade de Passos, no estado de Minas Gerais, a empresa tem como sua principal atuação o setor de construção civil e também atua no ramo de segurança com execução e projetos de combate a incêndio. Atualmente, emprega 15 funcionários no escritório empresarial, e conta com cerca de 220 prestadores de serviço, entre eles: pedreiros, serventes, calheiros, vidraceiros, eletricistas, entre outros do ramo civil. No primeiro semestre de 2016, a construtora possuía em torno de 70 obras em andamento.

Com o crescimento da empresa, mostra-se necessário uma melhor gestão dos seus processos. $\mathrm{O}$ assunto mais discutido no setor administrativo era a necessidade em se saber qual o lucro gerado na construção de cada casa. Nunca era possível obter um valor exato, devido à falha no processo de controle de custos. Depois de observações e análise dos processos da empresa, foi identificado que a causa raiz do problema se concentrava no almoxarifado, pois não se tinha o controle dos materiais usados em cada construção. Devido a isso, o setor escolhido para este trabalho, foi o de estoque, e a ferramenta $5 \mathrm{~S}$ foi adotada para implantação baseada nas afirmações de Vital et al. e Silva et al. (2015).

\subsection{Preparação para Implantação do Programa 5S}

Inicialmente foram realizadas visitas ao estoque e entrevistas com os colaboradores que se queixaram da desorganização do ambiente, falta de procedimentos padronizados, demora para encontrar os materiais e sujeira. Nas Figuras 1 e 2 são expostos o primeiro barracão de estoques antes da implantação da ferramenta $5 \mathrm{~S}$, sendo possível observar a desorganização no setor.

Afim de entender os métodos de trabalho, foi feito um levantamento dos recursos disponíveis e verificou-se que a empresa dotava de um sistema operacional conhecido como Contech que permite controlar o tipo e quantidade de produto estocado. Porém, esse sistema estava desatualizado, tornando-o inútil para controle. Conclui-se que os valores não estão acurados devido ao fato do relatório acusar quantidade negativa de produtos estocados.

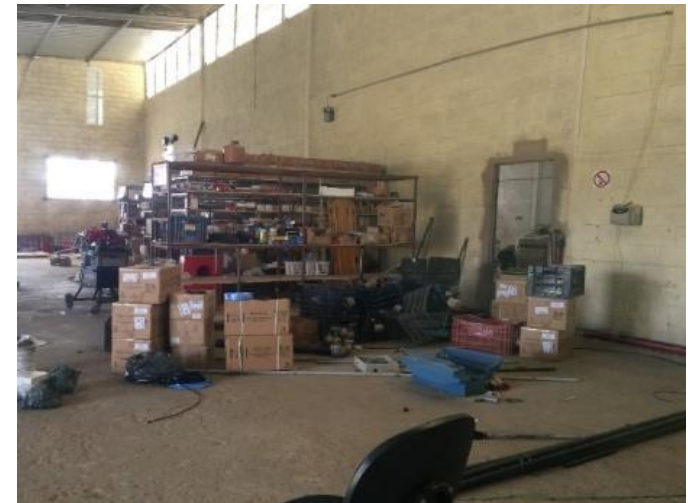

Figura 1 - Estoque antes do Programa 5S

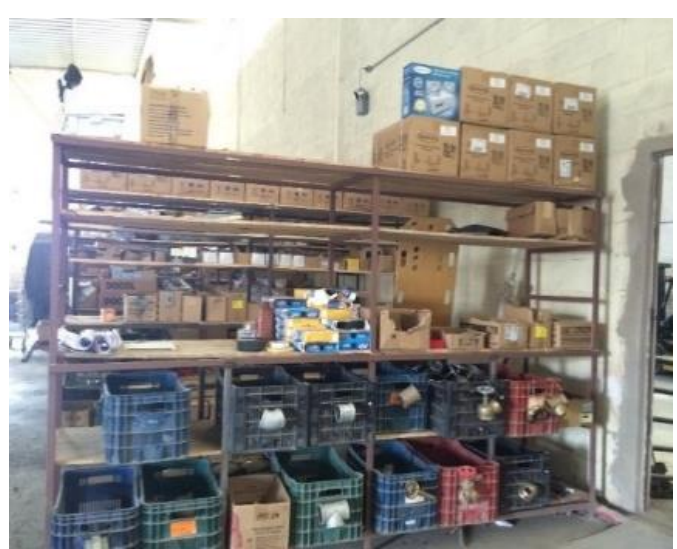

Figura 2 - Estoque antes do Programa 5S

Durante a coleta de dados, foi identificado um formulário que posteriormente era digitado em uma planilha de Excel e objetivava controlar os materiais que davam saída do estoque assim como seu destino final. Contudo, com o alto volume de pedidos de retirada de materiais e falta de procedimentos, muitas vezes este formulário não era preenchido, ocorrendo falha no sistema.

Finalmente, para comprovar que a desorganização era uma das causas que aumentava o tempo de procura dos materiais, 3 produtos (curva de 75, flange de 20 e suporte de extintor) foram selecionados aleatoriamente e 2 funcionários, um que conhecia o estoque e outro que não frequentava o setor (o auxiliar de serviços gerais e a secretaria), foram cronometrados realizando essa atividade.

Logo após a cronometragem, os funcionários foram questionados quanto à atividade desempenhada. Eles relataram que houve dificuldade na tarefa, pois os materiais não seguiam uma sequência. Além do mais, peças estavam misturada com outras, o que aumentou o tempo de procura. Outro fato mencionado pelo funcionário que não conhecia o estoque, foi a falta de identificação das peças. Por não conhecer tão bem as especificações dos materiais, ele ficou em dúvida quanto às dimensões requeridas. Por fim, outro fator considerado significativo foi a distância percorrida pelos colaboradores até as estantes. Desde a mesa do estoquista, onde são realizados os pedidos, até as estantes, o funcionário percorre até aproximadamente 15 metros. 


\subsection{Processo de Implantação do Programa 5S}

Para dar início à implantação, os dados coletados foram estudados e desenvolvido um plano de ação direcionando cada informação com um ñSò especifico da ferramenta baseada nas descrições feitas por Falconi (2004).

\subsubsection{Seiri-Senso de Seleção}

A implantação do programa teve início com a realização de um balanço no estoque. Nesta etapa, que é considerada difícil por Matos et al (2014), foram separados os materiais que são necessários e descartados os que já não são mais utilizados na empresa como pode ser observado na Figura 3. Alguns dos materiais que foram classificados como inúteis para a empresa, como por exemplo, os paletes e extintores vencidos, foram vendidos. Já outros produtos como por exemplo, caixas de papelão e conexões metálicas que já caíram em desuso, foram encaminhados para o local de coleta seletiva da cidade através do veículo de transporte de cargas da empresa (Figura 4), afim de possíveis reaproveitamentos.

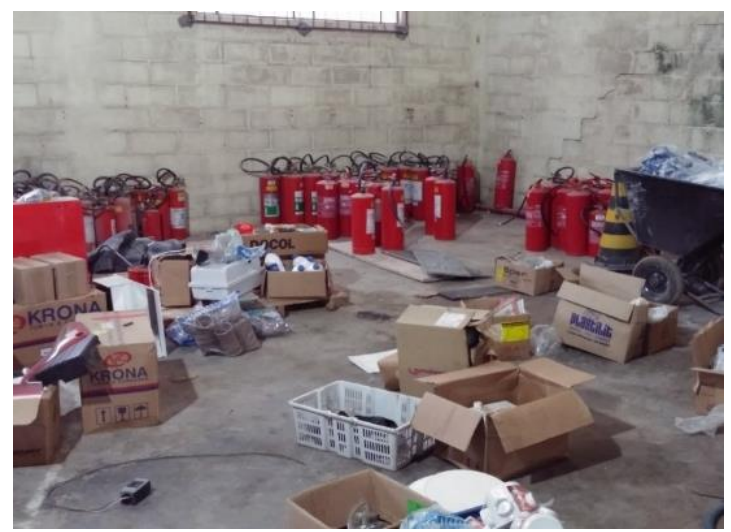

Figura 3 - Área de Descarte

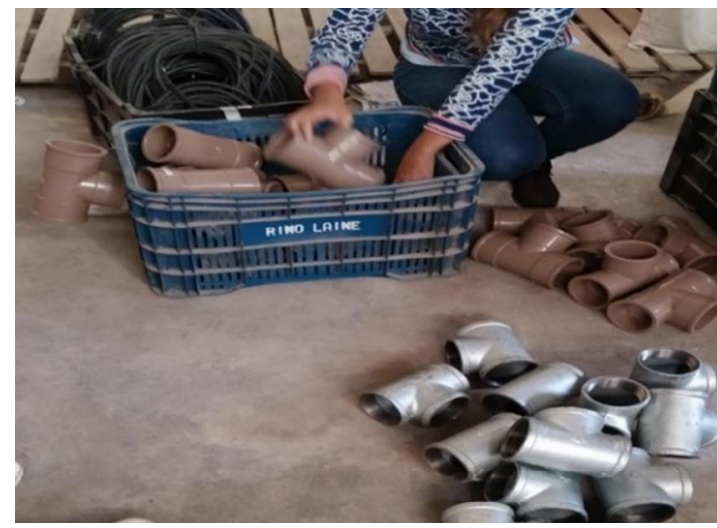

Figura 4-Momento de Contagem

Neste senso, os materiais classificados como necessários foram contabilizados e houve a atualização ou novo cadastro do produto no sistema Contech. Esta atualização do sistema passa a fornecer o tipo e número acurado dos produtos estocados. E para manter esta acurácia, toda vez que um produto der saída do estoque, também deverá efetivar a baixa no sistema. Além disso, o sistema mostrou possível incluir o preço do produto, então a oportunidade foi aproveitada e os preços de custo foram incluídos.
Após a contagem, foi possível obter um número exato de material estocado. A partir disso, foi possível desenvolver uma tabela demonstrando o custo unitário do produto que multiplicado por sua quantidade em estoque, gera custo total deste estocado.

\subsubsection{Seiton - Senso de Organização}

Nesta etapa o foco foi na organização, e o primeiro passo foi a mudança do layout do almoxarifado. Levando em consideração que mais do que organizar é necessário manter organizado, para evitar que qualquer pessoa que entre no setor de estoque tenha acesso aos materiais e o retire sem dar saída no sistema, foi construída uma bancada separando a área de circulação das prateleiras com os materiais.

Com a mudança, a mesa do estoquista foi deslocada para trás da bancada, assim, só ele terá acesso direto aos materiais. Conseguinte, as prateleiras foram distribuídas com espaçamento de 1 metro entre elas, e divididas em dois grupos: de incêndio e de construção civil. A partir dessa divisão foram definidos os locais para cada tipo de peça com base em sua classificação. Cestas foram compradas para melhor alocar as peças mais leves, pois além de fornecerem uma melhor organização visual, são mais resistentes do que caixas de papelões. A Figura 5 mostra como as peças eram armazenadas nas caixas de papelão e a Figura 6 apresenta como esse material foi distribuído em cestas organizadoras nas estantes.

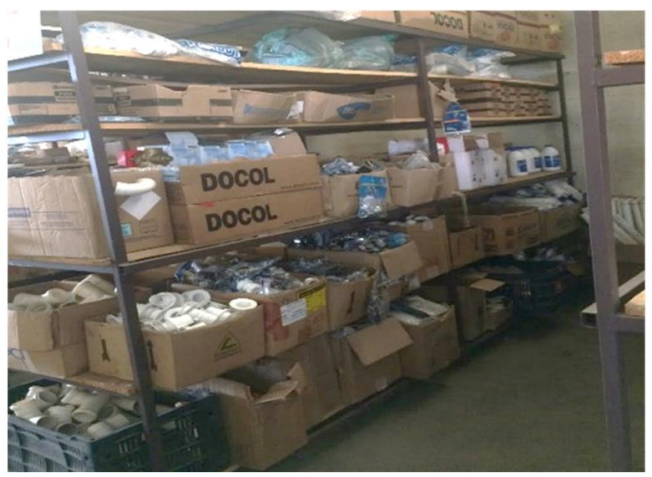

Figura 5 - Material Estocado em Caixas de Papelão

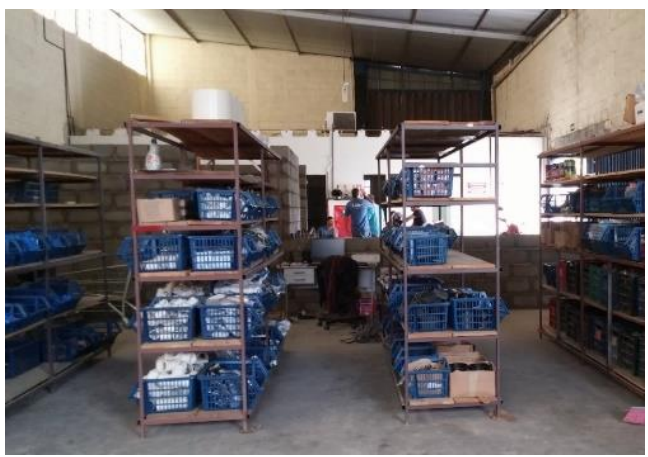

Figura 6- Material Estocado em Caixas Organizadoras

Depois de estabelecidos os locais de cada material, foram criadas primeiramente placas de identificação para as estantes. Estas etiquetas foram elaboradas seguindo a sistemática das iniciais de: Estante (E) e Coluna (C); seguido da numeração específica. Além disso, foram confeccionadas etiquetas para cada material contendo o nome do produto, 
localização e o número do item no sistema Contech. O código de localização foi definido baseado nas iniciais de: Estante (E), Coluna (C), e Fileira (F), conforme figura 7. Assim, as estantes, colunas e fileiras foram numeradas em ordem crescente e o sistema foi atualizado inserindo a localização de cada material.

Os materiais de porte grande, que não são apropriados para armazenamento em estantes, foram transferidos para outro barracão, que ficou definido como estoque de materiais pesados. Tais materiais também foram organizados em grupos, como pode ser visto nas Figuras 8.

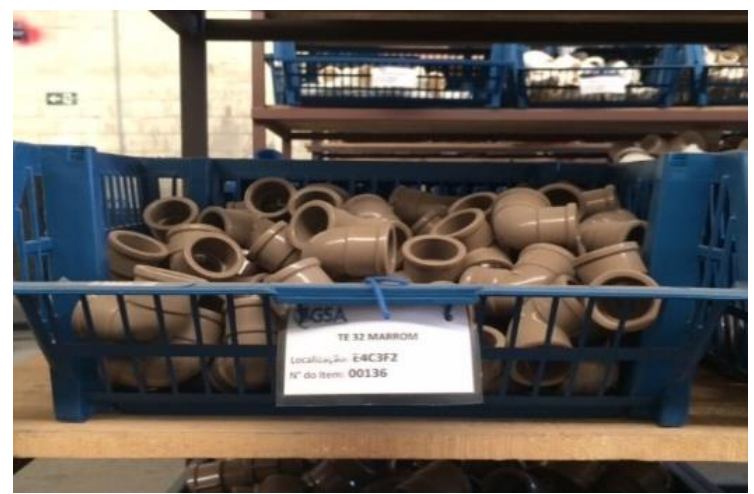

Figura 7 - Cesta com Etiqueta

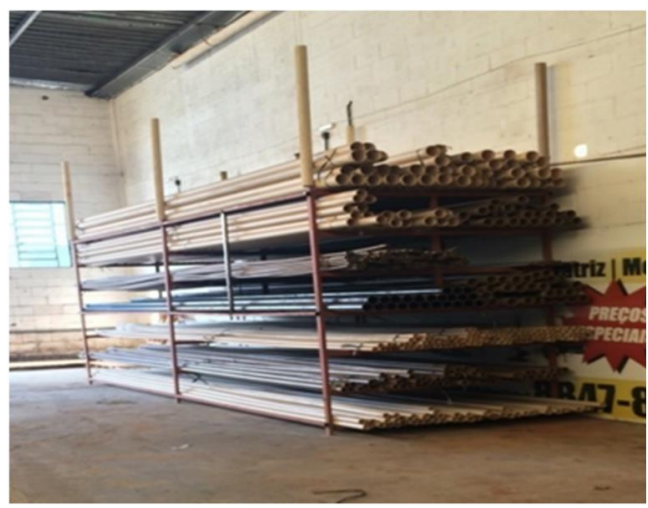

Figura 8 - Estoque de Canos

\subsubsection{Seiso - Senso de Limpeza}

Neste senso, uma limpeza geral foi realizada nos dois ambientes do setor de estoques, a fim de amenizar a sujeira que tanto incomoda os colaboradores que trabalham nesses ambientes. Para a limpeza, foram utilizados principalmente vassouras e pás, e os resíduos foram depositados no caminhão de cargas para descarte. Não somente o chão dos barracões foram limpos, mas também as estantes, mesas e quaisquer itens dispostos no ambiente.

\subsubsection{Seiketsu - Senso de Higienização}

O quarto ñSò objetiva a preservação de todas as conquistas anteriores zelando pela saúde, bem-estar, higienização, e a segurança dos colaboradores. Para isso, faz se necessário a criação de padrões e procedimentos para manter o programa funcionando. Dito isto, os procedimentos criados nesta etapa foram todos os materiais que chegarem à empresa, se já cadastrados no sistema, deverão ser adicionados no sistema e alocados ao lugar previamente estabelecido, os os materiais que chegarem à empresa, que não estiverem cadastrados no sistema, deverão ser cadastrados, alocados perto de um produto com mesma classificação, e uma etiqueta deverá ser confeccionada para tal material, os materiais que forem retirados deverão ter saída no sistema Contech a fim de manter a acurácia entre o físico e o digital, apenas o estoquista terá acesso ao estoque, sendo responsável pela entrada e saída dos materiais e a limpeza deverá ser realizada semanalmente.

Quanto à saúde e higienização, a primeira atitude tomada foi a reforma de um dos banheiros sanitários, a fim de fornecer um local apropriado e higiênico para que os funcionários possam realizar suas necessidades fisiológicas. Outra realização, foi a construção de uma cozinha equipada com pia, mesa e geladeira. Esta cozinha visa proporcionar condições adequadas e um ambiente agradável aos colaboradores no momento de suas refeições (almoço e café da tarde).

\subsubsection{Shitsuke - Senso de Disciplina}

Por fim, a práticas do $5 \mathrm{~S}$ se concretiza no dia a dia, até que vire hábito dos colaboradores de manter o ambiente sempre limpo e organizado. Para averiguar se as mudanças implementadas continuam sendo praticadas, foi elaborado um checklist, onde foi listado as principais atividades que devem ser frequentemente desempenhadas para manter o programa ativo e este será aplicado mensalmente.

O checklist apontará se todas as etapas estão sendo seguidas, e caso haja algum problema ou dificuldade no processo, uma reunião deverá ser realizada a fim de definir ações corretivas. Além disso, um quadro em branco foi instalado no setor com o intuito de fornecer aos colaboradores um espaço para expressarem suas opiniões e ideias de melhoria.

\subsection{Avaliação da Implantação}

O primeiro proveito obtido pôde ser verificado depois da aplicação do Senso de Seleção. Durante essa fase, um importante passo para a solução de um problema que a empresa enfrentava foi solucionado. Uma das dificuldades da empresa, era saber o tipo e quantidade de material preciso em estoque, o que foi solucionado depois da contagem e atualização do sistema. Após a implantação da ferramenta, o sistema apontou quantidades diferentes de produtos estocados.

Com isso, podemos comparar o as quantidades estocadas antes e depois da implantação, e nota-se que o custo anterior $(\mathrm{R} \$ 33318,23)$ para manter o estoque de tais materiais foi reduzido para $\mathrm{R} \$ 27.941,25$. Assim, conclui-se que antes da ferramenta $5 \mathrm{~S}$, haviam quantidades em excesso de materiais que caracteriza como desperdício não só de espaço, como também de custo.

Com o fim das cinco fases da ferramenta de organização, novos tempos foram coletados em ordem de certificar que o tempo dos colaboradores a procura de materiais foi reduzido. Assim, os mesmos funcionários que anteriormente tinham sido cronometrados se disporam a realizar esta atividade novamente, e os materiais requisitado foram os mesmos. A Tabela 4.4 mostra os novos tempos e realizou uma comparação entre os tempos obtidos antes e depois da implantação.

Desta forma, foi comprovado que o tempo gasto pelos colaboradores procurando materiais foi reduzido drasticamente. Um fator relevante para a redução desses tempos foi a mudança no layout físico. 
Com o novo layout, a distância percorrida pelo funcionário diminuiu em média 9,53 metros. Antes, a distância até a última prateleira era de 15 metros, e agora, a distância da mesa do estoquista até a estante mais distante é de 2,79 metros.

Visto isto, os fatores layout e organização foram cruciais para reduzir o tempo gasto pelos colaboradores procurando materiais. O Gráfico 1 mostra os tempos cronometrados antes e depois da implantação do programa, e pode ser inferido que com este novo sistema, uma pessoa que não conhece o setor também consegue encontrar os materiais em tempo aproximado ao de alguém que está familiarizado com o ambiente.

\section{CONSIDERAÇÕES FINAIS}

Este trabalho teve como objetivo melhorar a gestão de estoque em termos de aproveitamento de tempo e redução de desperdícios em uma construtora. Para isso, foi implantada a ferramenta $5 \mathrm{~S}$ que visa proporcionar um ambiente organizado, limpo e seguro.

Para desenvolver o trabalho foi necessário seguir cinco passos descritos na literatura referente ao Programa 5S Antemão ao início da implantação da ferramenta, realizou-se a coleta de dados através de entrevistas com os colaboradores e visitas ao estoque a fim de conhecer e avaliar o ambiente.

No primeiro passo, no senso de seleção já foi possível obter ganhos em questão de espaço, pois com a eliminação dos itens que não eram utilizados, foi liberado espaço nas prateleiras e no chão. Além do mais, os itens restantes foram contabilizados e houve uma atualização do sistema de controle que a empresa já possuía, o que gerou a acurácia da quantidade de material estocado.

O segundo senso trouxe mudanças no layout e na forma de armazenar os produtos. O método de organização criado, proporcionou uma fácil identificação dos materiais através das etiquetas e também foi umas das causas que levou a minimização de tempo buscando pelos objetos requeridos.

Posteriormente, o senso de limpeza não só promoveu um ambiente limpo aos colaboradores, como também forneceu suporte para manter essa conquista. Para isso, foi designada uma área contendo utensílios e materiais de limpeza.

Em seguida, no senso conhecido como de saúde, higiene ou padronização, foram criados padrões e procedimentos para manter a funcionalidade do programa, e com a construção da cozinha e reforma do banheiro foi possível fornecer um ambiente agradável e saudável para os funcionários. Além disso, nesse passo, foram distribuídos equipamentos de proteção individual e treinamentos a fim de assegurar a segurança dos colaboradores.

Por fim, na última etapa que objetivou verificar se os passos anteriores estavam sendo seguidos de acordo com diretrizes estabelecidas houve o desenvolvimento de um checklist. O checklist que será aplicado mensalmente, visa verificar se as atividades desenvolvidas continuam sendo exercidas.

De acordo com a proposta do trabalho, considera-se que seus objetivos foram atingidos. A implantação da ferramenta $5 \mathrm{~s}$ foi bem-sucedida promovendo ao setor de estoque da construtora uma melhor gestão, limpeza e organização. A acurácia da quantidade de material preciso em estoque, foi atingida no primeiro $\mathrm{S}$ da ferramenta, logo após a contagem e atualização do sistema. Os materiais passaram a ser facilmente identificados com o método de organização adotado. Com a mudança no layout e o ambiente organizado, foi possível reduzir o tempo gasto pelos funcionários procurando materiais. Ao fim da implantação, a ferramenta $5 \mathrm{~S}$ possibilitou ao estoquista uma melhor visualização do estoque permitindo que ele fizesse uma gestão melhor dos níveis de estoque.

A etapa de organização foi a fase que causou um maior impacto emocional nos colaboradores da empresa, principalmente nos que trabalham há mais tempo na organização. A princípio, houve resistência destes em aceitar que eles não seriam mais autorizados a retirar o material do estoque, pois agora somente o estoquista passou a ter esta autonomia. Por mais que a mudança pareça simples, afeta psicologicamente aqueles que estão acostumados a trabalhar sem regras.

Ao final deste trabalho constatou-se que a aplicação da ferramenta $5 \mathrm{~S}$ pode ser feita em empresas de diversos ramos de atuação. Além disso, este projeto pode contribuir cientificamente à literatura devido ao pequeno número de pesquisas relacionadas a aplicação dessa ferramenta em estoques de construtora.

Por fim, seria interessante a implantação do programa 5S em outros setores da empresa, como também em organizações de diferentes segmentos, pois existe uma escassez de trabalhos com essas técnicas em organizações de pequeno porte.

\section{REFERÊNCIAS}

ANTUNES, L.; ANTONIOLI FILHO, A.; CALARGE, F. A. A Melhoria da Gestão da Qualidade com Enfoque na Assistência Técnica: Um Estudo de Caso na Indústria da Construção Civil. In: ENCONTRO NACIONAL DE ENGENHARIA DE PRODUÇÃO, 35., 2015, Fortaleza. Anais do XXXV ENEGEP. Fortaleza: 2015, p.1-17.

COSTA, A. V. S.; SANTANA, A. V. N.; OLIVEIRA, J. M.; LUZ, M. C. M. Aplicação dos Princípios do Programa 5S em uma Loja de Materiais de Construção de Mãe do Rio/Pará. In: ENCONTRO NACIONAL DE ENGENHARIA DE PRODUÇÃO, 34., 2014, Curitiba. Anais do XXXIV ENEGEP. Curitiba: 2014, p.1-12.

COSTA, L. B. M., MONTE, V. M.; ESPOSTO, K. F. Mapeamento de Fluxo de Valor: Um Estudo de Caso em uma Farmácia Hospitalar. In: ENCONTRO NACIONAL DE ENGENHARIA DE PRODUÇÃO, 35., 2015, Fortaleza. Anais do XXXV ENEGEP. Fortaleza: 2015, p.1-13.

FARIA, A. F.; GALVÃO, M. F.; LEMOS, C. F. V. B.; RODRIGUES, M. F. C.; SUZUKI, J. A. Implantação do Programa 5S: Pesquisa-Ação em um Centro Tecnológico Público e Prestador de Serviço. In: ENCONTRO NACIONAL DE ENGENHARIA DE PRODUÇÃO, 34., 2014, Curitiba. Anais do XXXIV ENEGEP. Curitiba: 2014, p.1-17.

LAZZAROTTO, T. C.; PAZUCH, C. M.; BACK, L.; SCHUTZ, F. C. A. Proposta de Implantação do Programa 5S em um Laboratório de Industrialização de Vegetais da UTFPR Campus Medianeira. In: ENCONTRO NACIONAL DE ENGENHARIA DE PRODUÇÃO, 31., 2011, Belo Horizonte. Anais do XXXI ENEGEP. Belo Horizonte: 2011, p.1-9. 
MATOS, A. M. O.; LUCENA, K. S.; ALMEIDA, L. K. S.; SOUSA, L. F.; SILVA, A. M. Implantação da Ferramenta 5Sô no Almoxarifado de uma Empresa de Produção Agrícola, Localizada na Chapada do Apodi/CE. In: ENCONTRO NACIONAL DE ENGENHARIA DE PRODUÇÃO, 34., 2014, Curitiba. Anais do XXXIV ENEGEP. Curitiba: 2014, p.1-12.

MIGUEL, P. A. C. Estudo de caso na engenharia de produção: estruturação e recomendações para sua condução. Revista Produção, v. 17, n. 1, p. 216-229, jan./abr. 2007.

MIGUEL, P. A. C.; FLEURY, A.; MELLO, C. H. P.; NAKANO, D. N.; TURRIONI, J. B.; LEE HO, L.; MORABITO, R.; MARTINS, R. A.; PUREZA, V. Metodologia de pesquisa em engenharia de produção e gestão de operações. Rio de Janeiro: Elsevier, 2010.

OHNO, T. O Sistema Toyota de Produção - além da produção em larga escala. Porto Alegre: Artes médicas, 1997, 152p.

OLIVEIRA, R. S. S.; LIMA, K. L. S.; SOUTO NETO, T. P.; SANTOS, F.F. Proposta de Aplicação da Metodologia 5S: Um Estudo de Caso em uma Empresa de Manutenção de Motocicletas no Cariri Paraibano. In: ENCONTRO NACIONAL DE ENGENHARIA DE PRODUÇÃO, 35., 2015, Fortaleza. Anais do XXXV ENEGEP. Fortaleza: 2015, p.1-21.

SILVA, A. L. J.; RIBEIRO, L. L.; ASSUNÇÃO, M. V. D. Gerenciamento de Estoques de Grandes e Megaeventos: A Visão Estratégica como Forma de Organização. In: ENCONTRO NACIONAL DE ENGENHARIA DE PRODUÇÃO, 35., 2015, Fortaleza. Anais do XXXV ENEGEP. Fortaleza: 2015, p.1-15.

VITAL, A. F. M.; AZEVEDO, G. H.; SILVA, E. C.; TUTU, B. R. S. A Importância da Ferramenta 5S na Gestão de Materiais do Laboratório Didático de Pintura com Terra. In: ENCONTRO NACIONAL DE ENGENHARIA DE PRODUÇÃO, 35. 2015, Fortaleza. Anais do XXXV ENEGEP. Fortaleza: 2015, p.1-11.

WOMACK, J. P.; JONES, D. T. Lean Thinking: Banish Waste and Create Wealth in Your Corporation, Simon \& Schuster, September 1996.

WOMACK, J. P.; JONES, D. T.; ROOS, D. A máquina que mudou o mundo. $3^{\text {a }}$ Edição. Rio de Janeiro: Campus, 1992. 347p.

YIN, R. K. Estudo de caso - Planejamento e métodos. 3 Ed. Porto Alegre: Bookman, 2005. 